\title{
Survey of healthcare experiences of Australian adults living with rare diseases
}

\author{
Caron Molster ${ }^{1^{* \dagger}} \mathbb{D}$, Debra Urwin ${ }^{1 \dagger}$, Louisa Di Pietro ${ }^{2}$, Megan Fookes $^{3}$, Dianne Petrie ${ }^{4}$, Sharon van der Laan ${ }^{5}$ \\ and Hugh Dawkins ${ }^{1,6,7,8}$
}

\begin{abstract}
Background: Few studies have examined whether the healthcare needs of people living with rare diseases are being met. This study explores the experiences of Australian adults living with rare diseases in relation to diagnosis, information provision at the time of diagnosis, use of health and support services and involvement in research on their condition.
\end{abstract}

Methods: The survey respondents are self-selected from the population of Australian residents aged 18 years and over who are living with a rare disease. An online survey was implemented between July-August 2014. Purposive snowballing sampling was used. The results are reported as percentages with significant differences between sub-groups assessed using chi-squared analyses.

Results: Eight hundred ten responses were obtained from adults living with a rare disease. $92.1 \%$ had a confirmed diagnosis, of which $30.0 \%$ waited five or more years for a diagnosis, $66.2 \%$ had seen three or more doctors to get a diagnosis and $45.9 \%$ had received at least one incorrect diagnosis. Almost three quarters $(72.1 \%)$ received no or not enough information at the time of diagnosis. In the 12 months prior to the survey, over $80 \%$ of respondents had used the services of a general practitioner and a medical specialist while around a third had been inpatients at a hospital or had visited an emergency department. Only $15.4 \%$ of respondents had ever used paediatric services, $52.8 \%$ of these had experienced problems in the transition from paediatric to adult services. Only $20.3 \% \mathrm{knew}$ of a patient registry for their condition and $24.8 \%$ were informed of clinical trials.

Conclusions: These findings suggest that not all healthcare needs of people living with rare diseases are being met. Structural changes to Australian healthcare systems may be required to improve the integration and coordination of diagnosis and care. Health professionals may need greater awareness of rare diseases to improve the diagnostic process and support to meet the information requirements of people newly diagnosed with rare diseases. Health service use is likely higher than for the general population and further epidemiological studies are needed on the impact of rare diseases on the healthcare system.

Keywords: Healthcare, Survey, Australia, Experiences, Diagnosis, Health services, Rare diseases

\section{Background}

In terms of prevalence, a rare disease has been defined as one that is present in fewer than one person in 2000 in a population $[1,2]$. The range of rare diseases is very broad and around $80 \%$ are thought to be genetic in origin [1,3]. For example Alopecia areata is a complex genetic, immune mediated disease that results in partial

\footnotetext{
* Correspondence: caron.molster@health.wa.gov.au

${ }^{\dagger}$ Equal contributors

${ }^{1}$ Office of Population Health Genomics, Department of Health, Perth, WA, Australia

Full list of author information is available at the end of the article
}

to universal hair loss [4], while Kabuki syndrome is caused by a single mutation in one of two genes, and results in multiple congenital anomalies such as altered facial features, skeletal anomalies, growth deficiency and intellectual disability [5]. Although the aetiology and symptoms show great diversity, there are some commonalities across the range of rare diseases. For example, rare diseases often involve multi system dysfunction, require complex care, have no effective treatment, and are incurable [6-8]. Many are also associated with motor, sensory or intellectual impairment [9] 
and impose significant social, emotional and financial burdens on people living with rare diseases, and their carers and families [10, 11].

Stakeholder consultations with members of the Australian rare diseases community have indicated that common features across the range of rare diseases lead to similar needs from the health system $[12,13]$. This includes access to a wide range of health and social support services across primary, secondary and tertiary sectors $[13,14]$, along with:

- timely and accurate diagnosis;

- timely post-diagnosis information to inform decision-making about ongoing care;

- complex case management which requires access to a range of specialists, services and programs;

- coordinated and integrated care so that there are no gaps in service delivery across the lifespan, including transitions from paediatric to adult care;

- access to health professionals who are aware of, experienced with and knowledgeable about rare diseases; and

- access to infrastructure to support clinical, epidemiological and translational research, such as patient registries.

There are few studies that have examined whether such healthcare needs are being met for people living with rare diseases. Two studies conducted in the United Kingdom (UK) $[10,15]$ and Europe $[8,16]$ identify experiences of delayed diagnosis, misdiagnosis, a lack of information provided at the time of diagnosis, a lack of care coordination, problems with transition from paediatric to adult care and the prescription of incorrect medications. Anecdotally, Australians living with rare diseases have described similar experiences to those identified internationally. Yet to date there has only been a single published study with a small sample size and coverage restricted to paediatric patients diagnosed with genetic metabolic disorders. This study surveyed 30 families as a pilot study and found that $52 \%$ had consulted three or more doctors before receiving a correct diagnosis and $43 \%$ felt diagnosis was delayed [14].

The purpose of the present study was to explore the healthcare experiences of adults living with a rare disease in Australia. The Australian healthcare system includes a mix of public and private health services. There are no officially recognised centres of expertise for rare diseases, although some disease-specific clinics do exist. There is no national plan for rare diseases and only one state, Western Australia, has adopted a jurisdictional strategic framework for rare diseases [17]. Within this context, the objectives of the study were to examine experiences of diagnosis, perceptions of the information provided at the time of diagnosis, availability and use of health and support services, experiences during the transition from paediatric to adult health services and involvement in research.

\section{Methods \\ Survey instrument}

The survey was hosted online using the SurveyMonkey platform (SurveyMonkey Inc. Palo Alto, USA). The survey instrument was adapted with permission from the survey developed by Rare Diseases UK $[10,15]$. Some modifications were made to ensure that the questions were relevant in the Australian context, particularly relating to the primary, secondary and tertiary structure of the Australian healthcare system. A schematic diagram of the survey instrument is provided at Fig. 1. The full survey instrument is available from the authors upon request.

The survey instrument contains a majority of quantitative, close-ended questions with defined response categories. A smaller number of questions asked participants to provide qualitative information and for these an open-ended text box was provided. At the conclusion of each survey section, participants were also given the opportunity to provide any other comments they had on the section topic. Only data from the quantitative questions are reported in this paper.

The first section of the survey was used to obtain consent and to determine participant eligibility. Participants were provided with information about the survey, including the purpose, the agencies conducting the study and assurance around anonymity and aggregation of data for reporting purposes. They were then advised that by clicking the "next" button they were consenting to participate in the survey. As the survey was completed anonymously, once data was submitted by clicking the "submit" button at the end of the survey it was not possible to withdraw individual respondents' data.

The demographic section of the survey asked participants for information including gender, age and state of residence, the rare disease being lived with and the type of diagnosis that had been received (i.e., confirmed, unconfirmed or no diagnosis). Participants were also asked to rate their health, on a 5 point scale from excellent to poor. This question has previously been shown to be a reliable measure of general health [18] and is significantly associated with the relative risk of mortality [19].

The main body of the survey had four sections measuring key aspects of the health care experience, namely experiences of diagnosis, access to and use of health and support services, transition from paediatric to adult care settings and participation in research.

\section{Survey sampling}

Those eligible to complete the survey were Australian residents aged 18 years or older who are living with a 


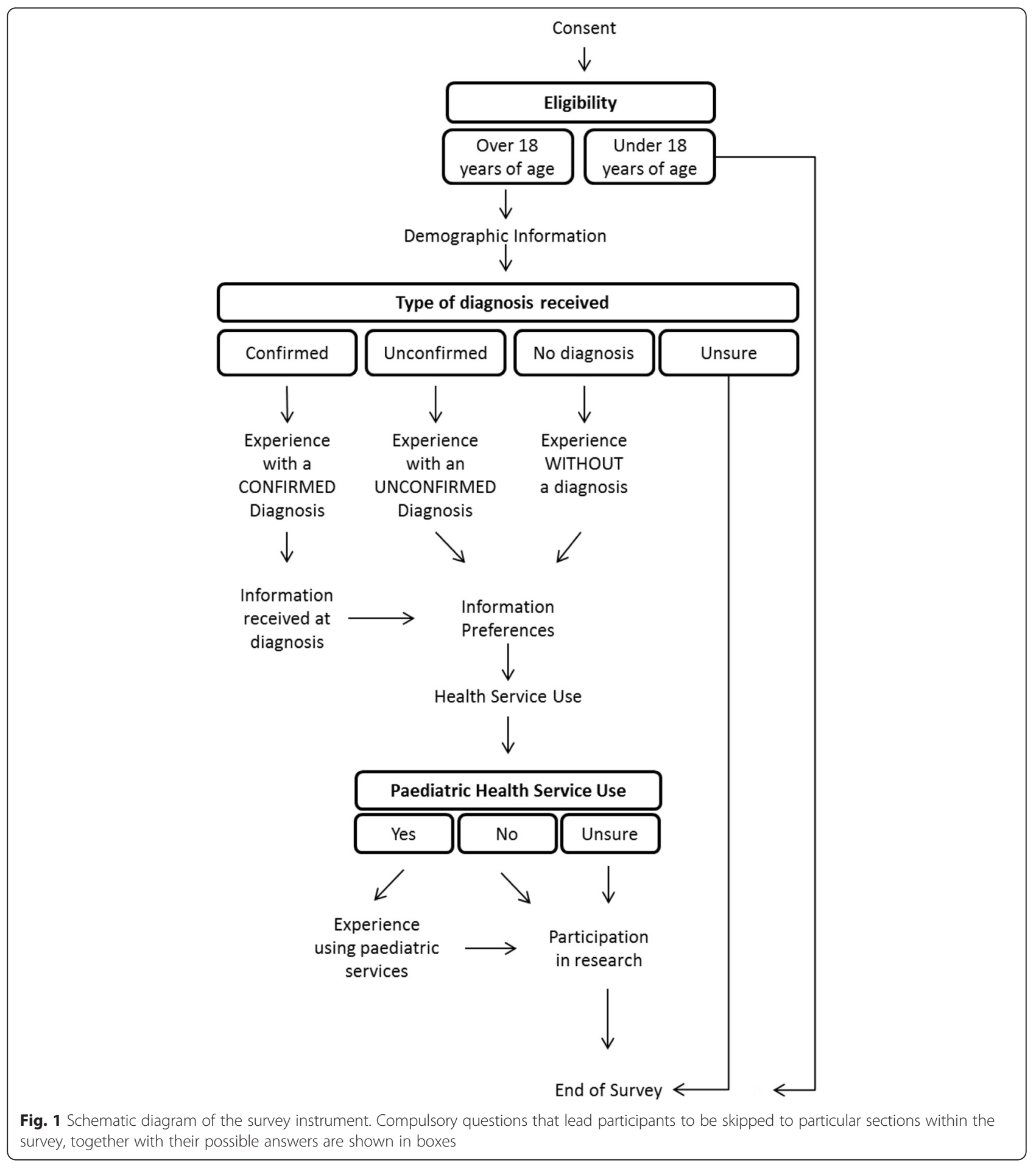

rare disease. Carers or paid support workers of people meeting these criteria were also invited to complete the survey, if the person living with a rare disease did not have the intellectual and/or physical capability to complete the survey themselves. The study was limited to adults living with rare diseases for two reasons. Firstly, the authors were aware that a survey of the healthcare experiences of children was being conducted simultaneously and did not want to over-burden the families and carers of children living with rare diseases with two similar surveys. Secondly, targeting the adult population enabled us to examine issues outside the paediatric healthcare system such as diagnosis and transition to using adult health services. 
To our knowledge a complete sample frame of all adults living with a rare disease in Australia does not exist. Unknown is the total number of people living with a rare disease, their contact details and their socio-demographic characteristics such as age, gender, highest education level and location of residence. For these reasons, purposive snowball sampling was used for this study. A link to the online survey was distributed via the networks and mailing lists of the Office of Population Health Genomics, within the Western Australian Department of Health and the four peak bodies in the Australian rare and genetic disease sector, namely Rare Voices Australia, Genetic Alliance Australia, Genetic Support Network Victoria and the Genetic and Rare Diseases Network. The survey link was initially distributed to over 300 patient support groups across Australia, as well as individuals registered with any of the collaborating organisations. Recipients of emails were asked to forward the link on to other people who were eligible for the survey. Because of the potential for participants to receive more than one invitation to participate, survey responses were limited to one per computer. Data were collected over a six week period during JulyAugust 2014.

\section{Data analysis}

SAS 9.2 survey analysis procedures for frequency tables were used to analyse the survey data (SAS Institute Inc. Cary, USA). The results are reported as percentages. Differences in responses associated with demographics were assessed for significance using chi-squared analyses.

\section{Results}

\section{Sample characteristics}

In total 1014 completed surveys were received. These were initially examined to confirm whether or not the diseases that respondents had reported having were rare. Alternative names and spellings were checked by referring to the Orphanet database of rare diseases (www.orpha.net). If the disease was listed in Orphanet with a prevalence of 1 in 2000 or less the respondent was deemed to be living with a rare disease. On this basis, 810 respondents were considered to be living with a rare disease. Most of the remaining respondents $(n=172)$ were living with a disease that typically has similar characteristics to a rare disease in that it is chronic and debilitating, but is more prevalent than 1 in 2000 people in the population. Others were removed from the study due to not meeting the age criteria, that is, they were aged less than 18 years.

Of the 810 respondents who were considered to be living with a rare disease, $92 \%$ had received a confirmed diagnosis. For the purposes of this study, a confirmed diagnosis is defined as a diagnosis that the doctor and patient are certain is correct based on a genetic (or other) test or clinical manifestation. Six percent had an unconfirmed diagnosis, defined as a diagnosis that the doctor and patient think is most likely to cause the symptoms experienced, but are not certain. The remainder had no diagnosis $(1.5 \%)$ or were unsure $(0.5 \%)$. In order to ensure we were examining the healthcare experiences of adults living with a rare disease, only those respondents with a confirmed diagnosis of a rare disease are included in the findings reported below.

Table 1 shows the demographic characteristics of survey respondents living with a confirmed rare disease. Responses were received from people located in all states and territories of Australia, and their numbers were

Table 1 Characteristics of the survey response group

\begin{tabular}{|c|c|c|}
\hline & $\begin{array}{l}\text { Number } \\
\text { of people }\end{array}$ & $\begin{array}{l}\% \text { of } \\
\text { Response }\end{array}$ \\
\hline \multicolumn{3}{|l|}{$\operatorname{Sex}(n=744)$} \\
\hline Female & 568 & 76.3 \\
\hline Male & 176 & 23.7 \\
\hline \multicolumn{3}{|l|}{ Age groups $(n=234)$} \\
\hline 18-34 years & 61 & 26.1 \\
\hline $35-64$ years & 129 & 55.1 \\
\hline 65 years and over & 44 & 18.8 \\
\hline \multicolumn{3}{|l|}{ State of residence $(n=741)$} \\
\hline New South Wales & 212 & 28.6 \\
\hline Victoria & 182 & 24.6 \\
\hline Queensland & 159 & 21.5 \\
\hline Western Australia & 92 & 12.4 \\
\hline South Australia & 44 & 5.9 \\
\hline Australian Capital Territory & 25 & 3.4 \\
\hline Tasmania & 23 & 3.1 \\
\hline Northern Territory & 4 & 0.5 \\
\hline \multicolumn{3}{|l|}{ Role of person answering the survey $(n=741)$} \\
\hline A paid support worker & 6 & 0.8 \\
\hline A person living with a rare disease. & 661 & 89.2 \\
\hline A relative/carer of a person with a rare disease & 74 & 10.0 \\
\hline Other & 0 & 0 \\
\hline \multicolumn{3}{|l|}{ Number of rare diseases per person $(n=746)$} \\
\hline 1 & 628 & 84.2 \\
\hline 2 & 93 & 12.5 \\
\hline 3 & 21 & 2.8 \\
\hline 4 & 4 & 0.5 \\
\hline \multicolumn{3}{|l|}{ Self-reported health status $(n=743)$} \\
\hline Excellent & 25 & 3.4 \\
\hline Very good & 113 & 15.2 \\
\hline Good & 211 & 28.4 \\
\hline Fair & 256 & 34.5 \\
\hline Poor & 138 & 18.6 \\
\hline
\end{tabular}


generally in proportion to the size of the population in each state and territory [20]. The age of respondents ranged from 18 to 87 years of age, with a median age of 47 years. The majority of respondents were female $(76.3 \%)$ and were themselves living with a rare disease $(89.2 \%)$, as opposed to being a relative/carer $(10.0 \%)$ or paid support worker $(0.8 \%)$. Almost one in five (18.6\%) reported their health as poor. Respondents reported living with up to four different rare diseases although $84 \%$ of respondents reported living with only one rare disease (Table 1).

A total of 185 rare diseases were represented (sub-types of a rare disease were combined together). Ninety-nine diseases had only one respondent, while the greatest number of responses for a single disease group $(n=52)$ was for Ehlers-Danlos syndrome, which has multiple sub-types. Table 2 provides a list of the diseases represented in the survey, as organised by nosological group based on the linearized Orphanet classifications [21]. The survey outcomes were not analysed by nosological disease groups, since there were 21 groups of diseases and the size of the sample in some groups was too small to detect significant differences in responses.

Table 2 Diseases represented in the confirmed rare disease group

\begin{tabular}{|c|c|c|c|}
\hline Rare disease groups $(n=746)$ & $\begin{array}{l}\text { Number } \\
\text { of people }\end{array}$ & $\begin{array}{l}\% \text { of } \\
\text { Response }\end{array}$ & $\begin{array}{l}\text { Diseases } \\
\text { in group }\end{array}$ \\
\hline Rare abdominal surgical disease & 1 & 0.1 & 1 \\
\hline Rare allergic diseases & 17 & 2.3 & 1 \\
\hline Rare bone disease & 5 & 0.7 & 4 \\
\hline Rare circulatory disease & 1 & 0.1 & 1 \\
\hline $\begin{array}{l}\text { Rare developmental defect during } \\
\text { embryogenesis }\end{array}$ & 80 & 10.7 & 37 \\
\hline Rare endocrine diseases & 39 & 5.2 & 10 \\
\hline Rare eye disease & 1 & 0.1 & 1 \\
\hline Rare gastroenterologic disease & 21 & 2.8 & 6 \\
\hline $\begin{array}{l}\text { Rare gynecologic or obstetric } \\
\text { disease }\end{array}$ & 1 & 0.1 & 1 \\
\hline Rare hematologic disease & 21 & 2.8 & 7 \\
\hline Rare hepatic disease & 9 & 1.2 & 2 \\
\hline Rare immune disease & 41 & 5.5 & 7 \\
\hline Rare inborn errors of metabolism & 50 & 6.7 & 13 \\
\hline Rare neoplastic disease & 11 & 1.5 & 8 \\
\hline Rare neurological disease & 263 & 35.3 & 45 \\
\hline Rare otorhinolaryngologic disease & 3 & 0.4 & 1 \\
\hline Rare renal disease & 6 & 0.8 & 2 \\
\hline Rare respiratory disease & 55 & 7.4 & 4 \\
\hline Rare skin disease & 22 & 3.0 & 12 \\
\hline $\begin{array}{l}\text { Rare systemic or rheumatologic } \\
\text { disease }\end{array}$ & 90 & 12.1 & 19 \\
\hline Unclassified & 9 & 1.2 & 3 \\
\hline
\end{tabular}

\section{Experiences of diagnosis}

Table 3 shows that of the respondents with a confirmed diagnosis, $17.4 \%$ had been diagnosed as children, that is between birth and 17 years of age, although this was higher for men compared to women $(24.6 \%$ versus $15.0 \%, p<0.01)$. A quarter $(25.2 \%)$ of respondents were diagnosed within three months of first seeking medical help, although this was higher for those diagnosed as children compared to those diagnosed as adults (43.4\% versus $21.8 \%, p<0.001)$. Around half the respondents $(51.2 \%)$ waited 1 year or more for a diagnosis, with almost one-third (30.0 \%) waiting five or more years.

Two-thirds of respondents (66.2 \%) had consulted three or more doctors to get a confirmed diagnosis (Table 3). The percentage was lower for people diagnosed as children compared to those diagnosed as adults $(50.4 \%$ versus $78.6 \%, p<0.001)$ and for men compared to women $(57.9 \%$ versus $68.2 \%, p<0.05)$. Almost half of the respondents $(45.9 \%)$ had received at least one incorrect diagnosis, that is, they were initially told they had a condition but were subsequently told they did not have that condition. This occurrence of incorrect diagnosis was lower for

Table 3 Experiences of diagnosis

\begin{tabular}{|c|c|c|}
\hline & $\begin{array}{l}\text { Number } \\
\text { of people }\end{array}$ & $\begin{array}{l}\% \text { of } \\
\text { Response }\end{array}$ \\
\hline \multicolumn{3}{|l|}{ Age at diagnosis $(n=732)$} \\
\hline $0-17$ years & 127 & 17.4 \\
\hline 18 years or more & 605 & 82.6 \\
\hline \multicolumn{3}{|l|}{ Time to diagnosis $(n=718)$} \\
\hline$<3$ months & 181 & 25.2 \\
\hline 3-12 months & 169 & 23.5 \\
\hline $1-5$ years & 153 & 21.2 \\
\hline $5-10$ years & 147 & 20.5 \\
\hline$>20$ years & 68 & 9.5 \\
\hline \multicolumn{3}{|l|}{$\begin{array}{l}\text { Number of doctors seen to get a confirmed } \\
\text { diagnosis }(n=735)\end{array}$} \\
\hline $1-2$ & 248 & 33.7 \\
\hline $3-5$ & 275 & 37.4 \\
\hline $6-10$ & 122 & 16.6 \\
\hline 11 or more & 90 & 12.2 \\
\hline \multicolumn{3}{|l|}{ Incorrect diagnosis $(n=737)$} \\
\hline At least one incorrect diagnosis & 338 & 45.9 \\
\hline No incorrect diagnosis & 360 & 48.8 \\
\hline Unsure & 39 & 5.3 \\
\hline \multicolumn{3}{|l|}{ Information on condition received $(n=742)$} \\
\hline Received no information & 141 & 19.0 \\
\hline Received some information but not enough & 394 & 53.1 \\
\hline Received enough information & 192 & 25.9 \\
\hline Unsure & 15 & 2.0 \\
\hline
\end{tabular}


respondents diagnosed as children compared to those diagnosed as adults ( $35.6 \%$ versus $51.2 \%, p<0.01$ ).

\section{Information provision at the time of diagnosis}

Around one in five respondents $(19.0 \%)$ had not received any information about their condition at the time of diagnosis (Table 3). Of the respondents who received information, $50.0 \%$ indicated that they understood all of the information provided (Table 4). The vast majority of those who received information were given this information by a medical specialist $(82.9 \%)$. Respondents who received information from a general practitioner (GP) were less likely to say they received enough information $(16.4 \%, p<0.01)$ while those who received information from a genetic counsellor were more likely to say they received enough information $(43.9 \%, p<0.05)$.

Almost one-third of respondents reported receiving verbal information only (31.2\%) or printed material $(32.1 \%)$ and $26.6 \%$ received a referral to a website. Those who received verbal information only were less likely to report they had understood all of the information provided $(42.8 \%, p<0.05)$ and that they received enough information $(21.9 \%, p<0.001)$, while people referred to a website were more likely to report they had understood all the information they were given $(64.7 \%$, $p<0.001)$ and that they had received enough information $(47.4 \%, p<0.001)$. Compared to respondents who

Table 4 Information received at the time of diagnosis ${ }^{\mathrm{a}}$

\begin{tabular}{|c|c|c|}
\hline & $\begin{array}{l}\text { Number } \\
\text { of people }\end{array}$ & $\begin{array}{l}\% \text { of } \\
\text { Response }\end{array}$ \\
\hline \multicolumn{3}{|c|}{ Understanding of information provided $(n=578)$} \\
\hline Did not understand all the information & 289 & 50.0 \\
\hline Understood all the information & 289 & 50.0 \\
\hline \multicolumn{3}{|l|}{ Who provided information ${ }^{\mathrm{b}}(n=578)$} \\
\hline General practitioner & 73 & 12.5 \\
\hline Medical specialist & 486 & 82.9 \\
\hline Genetic counsellor & 82 & 14 \\
\hline Allied health professional & 16 & 2.7 \\
\hline Other & 42 & 7.2 \\
\hline \multicolumn{3}{|l|}{$\begin{array}{l}\text { Format of information provided at diagnosis }{ }^{b} \\
(n=578)\end{array}$} \\
\hline Printed material (e.g., brochures, leaflet) & 188 & 32.1 \\
\hline Referred to website & 156 & 26.6 \\
\hline Social media & 87 & 14.8 \\
\hline Journal article & 79 & 13.5 \\
\hline Verbal only ${ }^{c}$ & 183 & 31.2 \\
\hline Other & 9 & 1.5 \\
\hline
\end{tabular}

${ }^{a}$ Among respondents who received information at the time of diagnosis $(n=586)$

${ }^{\mathrm{b}}$ Multiple responses reported

'Respondents were not given this option to choose. Instead it was nominated as a response to the option 'other' received only one source of information, those provided with two or more sources of information were more likely to report the information provided was enough ( $43.3 \%$ versus $22.1 \%, p<0.001)$ and that it was understood $(61.2 \%$ versus $46.7 \%, p<0.01)$.

\section{Preferred information formats, information sources, knowledge and the use of support groups}

Of the options provided in the survey, $77.6 \%$ percent of respondents reported that referral to a website was the most preferred format of information on their condition (Table 5), followed by social media (56.2\%), printed materials such as brochures or leaflets $(52.4 \%)$ and journal articles (49.3\%).

At the time of the survey, the main sources of information available to respondents on their condition were medical specialists $(60.7 \%)$, patient organisations $(39.0 \%)$ and other people or families (35.1\%, Table 5). Six in ten respondents $(59.4 \%)$ had a specific person they could consult with questions on their condition however $27.3 \%$ did not think they now have sufficient knowledge of their condition. Of those who did have someone to ask questions, the vast majority said this person is a medical specialist. In the 12 months prior to the survey, $53.5 \%$ of respondents had used the services of a patient organisation or support group.

\section{Access to and use of healthcare and other services}

Table 6 shows that the majority of respondents agreed that they received sufficient medical support $(66.4 \%)$ but fewer agreed they received sufficient social (34.1\%), financial (14.5 \%) and psychological (20.6 \%) support. In the 12 months prior to the survey, 8 in 10 respondents had used the services of a GP $(81.1 \%)$ and a medical specialist $(81.4 \%)$ at least once (Table 7$), 40.3 \%$ had used an outpatients service or clinic, while around a third had been inpatients at a hospital $(28.0 \%)$ or had visited an emergency department (33.4\%). This level of service use is higher than that reported for the general population of Australians aged 15 years and older [22], where $35 \%$ had visited a medical specialist, $9 \%$ had used an outpatient service, $13 \%$ had been an inpatient at hospital and $12 \%$ had used an emergency department.

Nearly four in ten $(38.8 \%)$ consulted three or more specialists for their ongoing care yet only $9.2 \%$ had a designated care coordinator (Table 8). Similarly, $39.1 \%$ travelled more than $50 \mathrm{~km}$ to see their medical specialists, while only $3.9 \%$ had used telehealth services. One-fifth (22.1\%) knew of a specialist centre for their condition and the majority of these respondents had used that centre. Overall, $37.0 \%$ were satisfied with the adult services they used while $25.2 \%$ were dissatisfied and $37.8 \%$ neither satisfied nor dissatisfied. 
Table 5 Information, knowledge and use of support groups

\begin{tabular}{|c|c|c|}
\hline & $\begin{array}{l}\text { Number } \\
\text { of people }\end{array}$ & $\begin{array}{l}\% \text { of } \\
\text { Response }\end{array}$ \\
\hline \multicolumn{3}{|l|}{ Preferred format for information ${ }^{a}(n=746)$} \\
\hline Referred to website & 579 & 77.6 \\
\hline Social media & 419 & 56.2 \\
\hline Printed material (e.g., brochures, leaflet) & 391 & 52.4 \\
\hline Journal article & 368 & 49.3 \\
\hline Book & 257 & 34.5 \\
\hline DVD & 188 & 25.2 \\
\hline Other & 67 & 9.0 \\
\hline \multicolumn{3}{|l|}{ Main source of information ${ }^{\mathrm{a}}(n=746)$} \\
\hline Medical specialist & 453 & 60.7 \\
\hline Patient organisation & 291 & 39.0 \\
\hline Other people or families & 262 & 35.1 \\
\hline Own research & 112 & 15.0 \\
\hline GP & 86 & 11.5 \\
\hline Genetic councilor & 44 & 5.9 \\
\hline Allied health professional & 38 & 5.1 \\
\hline Other & 202 & 27.1 \\
\hline \multicolumn{3}{|l|}{$\begin{array}{l}\text { Now have sufficient knowledge of condition } \\
(n=744)\end{array}$} \\
\hline Yes & 437 & 58.7 \\
\hline No & 203 & 27.3 \\
\hline Don't know & 104 & 14.0 \\
\hline \multicolumn{3}{|l|}{$\begin{array}{l}\text { Have a specific person to ask questions about } \\
\text { condition }(n=737)\end{array}$} \\
\hline Yes & 438 & 59.4 \\
\hline No & 299 & 40.6 \\
\hline \multicolumn{3}{|l|}{$\begin{array}{l}\text { Have used a patient support group in past } \\
12 \text { months }(n=620)\end{array}$} \\
\hline Daily & 62 & 10.0 \\
\hline Weekly & 47 & 7.6 \\
\hline Monthly & 53 & 8.6 \\
\hline Several times & 98 & 15.8 \\
\hline Once or twice & 72 & 11.6 \\
\hline Never & 288 & 46.5 \\
\hline
\end{tabular}

${ }^{\mathrm{a}}$ Multiple responses reported

Table 6 Received sufficient support

\begin{tabular}{lcccl}
\hline & Agree & $\begin{array}{c}\text { Neither agree } \\
\text { nor disagree }\end{array}$ & Disagree & Don't know \\
\hline Medical $(n=624)$ & 66.4 & 18.9 & 14.6 & - \\
Social $(n=709)$ & 34.1 & 25.4 & 40.6 & - \\
Financial $(n=725)$ & 14.5 & 21.1 & 61.0 & 3.4 \\
Psychological $(n=727)$ & 20.6 & 26.3 & 50.3 & 2.8 \\
\hline
\end{tabular}

Table 7 Health services used at least once in the 12 months prior to survey

\begin{tabular}{|c|c|c|c|c|c|}
\hline Service used & $\mathrm{n}^{\mathrm{a}}$ & $\begin{array}{l}\text { \% of total } \\
\text { sample }\end{array}$ & Median $^{b}$ & Mode $^{b}$ & Range $^{\mathrm{b}}$ \\
\hline General Practitioner & 605 & 81.1 & 6 & 2 & $1-100$ \\
\hline Allied Health & 286 & 38.3 & 5 & 2 & $1-250$ \\
\hline Medical Specialist & 607 & 81.4 & 2 & 2 & $1-365$ \\
\hline Emergency Department & 249 & 33.4 & 4 & 1 & $1-32$ \\
\hline Hospital Outpatients/Clinics & 301 & 40.3 & 4 & 1 & $1-100$ \\
\hline Hospital Inpatients & 209 & 28.0 & 2 & 1 & $1-365$ \\
\hline Dental Services & 236 & 31.6 & 2 & 1 & $1-31$ \\
\hline Mental Health Services & 207 & 27.7 & 5 & 1 & $1-52$ \\
\hline Alternative Health Services & 173 & 23.2 & 5 & 1 & $1-175$ \\
\hline
\end{tabular}

\section{Experiences of paediatric services and the transition to} adult services

Fifteen percent of respondents had ever used paediatric services (Table 8). Just over half of these respondents $(57.0 \%)$ were satisfied with the care they had received from paediatric services, while $10.6 \%$ were dissatisfied and $32.5 \%$ were neither satisfied nor dissatisfied. Half of respondents who had used a paediatric health service were satisfied with the time between the last paediatric visit and the first visit to adult services (49.5\%) while $25.2 \%$ were dissatisfied. Half had experienced problems in the transition from paediatric to adult services (52.8\%). Transition is most often defined as "the purposeful, planned movement of adolescents and young adults with chronic physical and medical conditions from child-centred to adult-oriented health care systems" [23].

\section{Participation in research}

Patient registries are sets of clinical and non-clinical data stored in an organised, systemic manner [24]. They can be used to build knowledge about rare disease diagnosis, treatment and management, and enable access to clinical trials of drug treatments and other therapies that are being developed [25, 26]. Only $20.3 \%$ of survey respondents knew of a patient registry for their condition, yet $88.6 \%$ indicated they would join a registry if one existed (Table 9). Of those respondents who know of a patient registry for their condition, $90.6 \%$ had joined that registry.

One-quarter $(24.8 \%)$ of respondents reported they are informed of clinical trials for their condition while fewer agreed that they were given enough information on clinical trials $(16.6 \%)$ or on research in general into their condition (19.3\%). One-third (33.2\%) had participated in research into their condition, with the most common 
Table 8 Health service experiences

\begin{tabular}{lll}
\hline & $\begin{array}{l}\text { Number } \\
\text { of people }\end{array}$ & $\begin{array}{l}\% \text { of } \\
\text { Response }\end{array}$ \\
\hline
\end{tabular}

Number of specialists seen for ongoing care and treatment $(n=730)$

$1-2$

447

3-4

5-6

More than 6

Don't know

Designated care coordinator $(n=742)$

Yes

No

Don't know

Distance travelled to see medical specialists $(n=734)$

$<20 \mathrm{~km}$
$20-50 \mathrm{~km}$
$51-100 \mathrm{~km}$
$101-200 \mathrm{~km}$
$201-500 \mathrm{~km}$
$>500 \mathrm{~km}$

Use telehealth services $(n=741)$

Yes

No

Don't know

Know of a specialist centre for the condition $(n=738)$

Yes

No

Unsure

Overall satisfaction with adult health services $(n=674)$

Very satisfied
Satisfied
Partly satisfied and partly dissatisfied
Dissatisfied
Very dissatisfied
Had ever used paediatric services $(n=746)$

Yes

No

Don't know

Overall satisfaction with paediatric health services $^{\mathrm{a}}(n=114)$

Very satisfied

Satisfied
33.0

27.8

12.0

9.2

8.0

9.9

3.9

94.0

2.0

15

163

22.1

51.2

26.7

197

70

179

255

\section{2} 4.0 5

2

2

87.4

3.5

Table 8 Health service experiences (Continued)

\begin{tabular}{lcc}
\hline Partly satisfied and partly dissatisfied & 37 & 32.5 \\
Dissatisfied & 6 & 5.3 \\
$\quad$ Very dissatisfied & 6 & 5.3 \\
$\begin{array}{l}\text { Satisfied with time between last paediatric } \\
\text { and first adult visit }{ }^{\mathrm{a}}(n=103)\end{array}$ & \\
Yes & 51 & 49.5 \\
No & 26 & 25.2 \\
Don't know & 26 & 25.2 \\
Problems in transition from paediatric to & & \\
adult services ${ }^{\mathrm{a}}(n=108)$ & & \\
Yes & 57 & 52.8 \\
No & 38 & 35.2 \\
Don't know & 13 & 12.0 \\
\hline among respondents who had ever used paediatric services $(n=115)$
\end{tabular}

${ }^{\mathrm{a} A m o n g}$ respondents who had ever used paediatric services $(n=115)$

form of participation being the provision of biological samples for research, followed by being on a registry and participating in a clinical trial.

\section{Discussion}

Consistent with previous studies conducted in the United Kingdom and Europe [8, 10, 16, 27], around half of the respondents in the current study waited one year or more to be diagnosed with a rare disease, with almost a third waiting five or more years. Two-thirds consulted three or more doctors before receiving a confirmed diagnosis and almost half were given an incorrect diagnosis prior to their final diagnosis. This is problematic in that the absence of an early, accurate diagnosis can contribute to unnecessary or delayed treatment, poorer health outcomes, reduced quality of life, unnecessary hospital admissions and thus inefficient use of health system resources $[8,16,28-30]$.

It can be assumed that clinicians work hard to deliver timely, accurate diagnoses for their patients and that a long wait for diagnosis can, at least in part, be attributed to the nature of rare diseases. Most are complex with multi-system dysfunction and thus may require a diagnostic process that involves multiple medical specialties and a systematic method of precluding conditions before arriving at a final diagnosis. However it is also possible that structural features within health systems could contribute to inefficiencies and gaps in the diagnostic process.

Fragmentation and the siloed nature of Australian health systems, organised by medical specialties, could lead to lack of communication between specialties and the experience of patients not being considered as a 'whole person', both at the time of diagnosis and during ongoing care and disease management. This possibility suggests that components of the health system need to 
Table 9 Research on condition

\begin{tabular}{|c|c|c|}
\hline & $\begin{array}{l}\text { Number } \\
\text { of people }\end{array}$ & $\begin{array}{l}\% \text { of } \\
\text { Response }\end{array}$ \\
\hline \multicolumn{3}{|l|}{ Would join registry if one existed $(n=741)$} \\
\hline Yes & 657 & 88.6 \\
\hline No & 13 & 1.8 \\
\hline Don't know & 71 & 9.6 \\
\hline \multicolumn{3}{|l|}{ Know of a patient registry $(n=737)$} \\
\hline Yes & 150 & 20.3 \\
\hline No & 587 & 79.7 \\
\hline \multicolumn{3}{|l|}{$\begin{array}{l}\text { Joined a patient registry that they know of a } \\
(n=149)\end{array}$} \\
\hline Yes & 135 & 90.6 \\
\hline No & 4 & 2.7 \\
\hline Unsure & 9 & 6.0 \\
\hline Would prefer not to say & 1 & 0.7 \\
\hline \multicolumn{3}{|l|}{ Informed of clinical trials $(n=741)$} \\
\hline Yes & 184 & 24.8 \\
\hline No & 515 & 69.5 \\
\hline Don't know & 42 & 5.7 \\
\hline \multicolumn{3}{|l|}{$\begin{array}{l}\text { Given enough information about clinical trials } \\
(n=728)\end{array}$} \\
\hline Yes & 121 & 16.6 \\
\hline No & 487 & 66.9 \\
\hline Don't know & 120 & 16.5 \\
\hline \multicolumn{3}{|l|}{$\begin{array}{l}\text { Given enough information about research in } \\
\text { general }(n=735)\end{array}$} \\
\hline Yes & 142 & 19.3 \\
\hline No & 520 & 70.8 \\
\hline Don't know & 73 & 9.9 \\
\hline \multicolumn{3}{|l|}{ Ever participated in research $(n=746)$} \\
\hline Yes & 248 & 33.2 \\
\hline No & 479 & 64.2 \\
\hline Unsure & 19 & 2.5 \\
\hline \multicolumn{3}{|l|}{ Type of research participation $n^{\mathrm{b}, \mathrm{c}}(n=248)$} \\
\hline Being on a registry & 90 & 36.3 \\
\hline Clinical trial & 81 & 32.7 \\
\hline Recruiting others to participate in clinical trials & 17 & 6.9 \\
\hline Providing samples for research & 139 & 56.0 \\
\hline Patient representative & 10 & 4.0 \\
\hline Survey & 25 & 10.1 \\
\hline Other & 27 & 10.9 \\
\hline
\end{tabular}

among those who know of a patient registry for their condition $(n=150)$ ${ }^{\mathrm{b}}$ Among those who had participated in research $(n=260)$

'Multiple responses reported

be better integrated and individual care for people living with rare diseases to be better coordinated [29, 31, 32]. Aligned with this, the role of multi-disciplinary centres of expertise in rare disease requires exploration in the Australian context.

Internationally multi-disciplinary centres have been promoted as mechanisms to bring together health professionals from a range of medical and allied health disciplines. The aim is to provide a team-based approach that integrates services for diseases diagnosis, follow-up and management and enable a continuum of care and care coordination for people living with rare diseases [33-35]. Mental health professionals should be considered a key part of a multi-disciplinary approach, given half of our respondents' perceived they did not receive sufficient psychological support.

Structural issues may be particularly pertinent for adult health services when compared with paediatric services. The present study found that respondents diagnosed as children were more likely to have been diagnosed within three months, to see fewer doctors before receiving a confirmed diagnosis and they were less likely to receive an incorrect diagnosis. While this could be due to the nature of the diseases and symptoms that onset in childhood compared to adulthood, it could also be due to differences in the structure and operations of paediatric and adult care settings in Australia. Paediatric settings are generally more likely to involve family and carers, have shorter wait times, fewer patients, general paediatricians who cut across specialty areas, multi-disciplinary teams and specialists knowledgeable in rare diseases.

The differences in care settings may also contribute to the problems experienced by a significant number of respondents who needed to transition from paediatric to adult care. Poor transition can influence patterns of integration into adult health services (e.g., not making or keeping appointments) and reduce adherence to treatments, both of which can result in poorer health outcomes [36]. To the extent that there is a lag between the time of transition and when the survey was completed, it is possible that respondent views on the transition experience are associated with recall bias. Thus the reliability of this data must be approached with caution. However, previous Australian findings [37] have also identified the need for improved transition for people living with rare diseases, including better preparation and planning for transition, continuity and coordination of care including the sharing of patient records and medical history, flexibility to allow the involvement of parents and carers and access to transition coordinators.

Health professionals may need greater awareness of rare diseases in order to improve the diagnostic process, and support to meet the information requirements of people newly diagnosed with rare diseases. With 5000 or more rare diseases, it is unrealistic to expect that health professionals would know about every rare disease. However, 
education could be provided to reinforce to health professionals that when they see a patient whose symptoms they can't explain, usual practice is to ask whether the cause could be a rare disease. This approach to education seems appropriate since patients have reported that accelerating a correct diagnosis requires the crucial step of recognising their disease is not one frequently encountered but possibly a rare disease [25].

When compared to data on Australians aged 15 years and older from the Australian Health Survey [22], the respondents to the current survey appear more likely to have seen a medical specialist, been an inpatient at hospital, used an outpatient service or used an emergency department. This suggests that health service use may be higher among people living with rare diseases compared to the general population. This claim is supported with a study by Dye et al. (2011) which found that adults living with rare genetic disorders had increased numbers of hospital admissions and longer lengths of stay [38]. Thus the health system costs attributable to rare diseases may be disproportionately high compared to the size of the population living with rare diseases. Information on the impact of rare diseases on the health system is critical for planning services that respond to the needs of people living with rare diseases and epidemiological studies are required to investigate this further.

In this study respondents indicated an overwhelming desire to be involved in research into their condition. In particular, $90 \%$ respondents indicated that they would join a patient registry if one existed for their condition. In Australia, interest in patient registries has grown significantly among clinicians, researchers, industry and patient organisations since registries facilitate research into rare diseases and are particularly important in supporting patient access to local, national and international clinical trials of new drug treatments and therapies [26, 39]. While there are numerous disease specific registries in Australia, these tend to be siloed and lack interoperability. There have been calls for a national registry in Australia for all rare diseases, similar to those developed in other countries [40]. Based on the findings of this study, people living with rare diseases would seem likely to join a disease-specific and/or a national registry, if the existence of such a registry is communicated to them.

It is not possible to determine the generalizability of the results from this study to the total population of people living with a rare disease. There is a paucity of evidence regarding the total number of people living with a rare disease in Australia, and their characteristics such as gender, age distribution, level of education and socio-economic status are unknown. Respondents to this study were self-selected after receiving an email about the survey, most likely from a patient support organisation that was on the distribution list of one or more of the study partners. Thus people without links to a patient support organisation that was known to the study partners will be under-represented in the survey respondents, as will those without a computer/email address and those with lower e-health literacy.

It is assumed that the high proportion of female respondents to the study is over-representative. This may be due to the fact that women are more likely to respond to surveys or the fact that people were recruited to the study through patient organisations to which women may be more likely to belong. While this may bias the survey findings, comparisons to male respondents indicated there were few areas of reported healthcare experiences with significant differences between men and women. An exception to this was the higher percentage of men being diagnosed with a rare disease in childhood and this warrants further investigation.

In relation to age, while it was compulsory for respondents to answer whether or not the person living with a rare disease was aged 18 years or over, it was not compulsory to provide details of actual age in years and relatively few respondents chose to do so $(n=257,31.7 \%$ of the sample). We are not sure why this is the case but as a result it was unreliable to conduct an analysis of survey outcomes by age groups. It is possible that outcomes would be different across age groups, given that health services have likely changed over the course of time, and this could be further investigated.

Sample bias may also exist in relation to the type of diseases which were represented among the study respondents. Some conditions, such as Ehlers-Danlos syndrome, were over-represented in relation to the total sample size. Similarly, it's possible that more severe disorders, such as those that lead to major incapacity and/or early death, are under-represented. Despite this, survey respondents did represent a range of rare diseases and commonalities in healthcare experiences were identified that cut across disease types. This suggests that considering rare diseases as a collective group is an efficient way for health service providers and policy-makers to respond to the public health issue of rare diseases. In a health system that is oriented towards more common diseases, a collective view should serve to raise the profile of rare diseases and is likely to result in less duplication of efforts and resources across the range of rare diseases.

\section{Conclusion}

This study of 746 survey respondents addresses a gap in the literature regarding the healthcare experiences of Australian adults living with a confirmed rare disease and suggests that not all of their healthcare needs are being met. In line with the study findings, calls for a 
national plan for rare diseases in Australia [7, 12, 13, 41] have suggested that a national plan should support: patient-centric, integrated, coordinated, multi-disciplinary care; the information needs of people living with rare diseases, their carers, families and health professionals; training for health professionals so that they can better identify rare diseases; and the development of research infrastructure such as patient registries which are easily accessible for people living with rare diseases. The current study provides some much needed evidence to support an emphasis on these issues in national planning for rare diseases in Australia.

\section{Ethics approval and consent to participate}

Ethics approval was obtained from the Western Australian Department of Health, Human Research Ethics Committee (approval number 2014/03).

\section{Competing interests}

The authors declare that they have no competing interests.

\section{Authors' contributions}

CM conceived the study. CM, DU, MF, LDP, SVDL and DP contributed to the design of the study and the acquisition of data. CM and DU contributed to the analysis and interpretation of data. All authors contributed to the drafting of the manuscript or revised it critically, and have given final approval of the version published.

\section{Acknowledgements}

The authors would like to acknowledge the participants in this study and thank them for providing information on their healthcare experiences. This study was funded through in-kind support from the Office of Population Health Genomics, Rare Voices Australia, Genetic Alliance Australia, Genetic Support Network Victoria and Genetic and Rare Diseases Network.

\section{Author details}

'Office of Population Health Genomics, Department of Health, Perth, WA, Australia. ${ }^{2}$ Genetic Support Network Victoria, Melbourne, VIC, Australia. ${ }^{3}$ Rare Voices Australia, Sydney, NSW, Australia. ${ }^{4}$ Genetic Alliance Australia, Sydney, NSW, Australia. ${ }^{5}$ Genetic and Rare Diseases Network, Perth, WA, Australia. ${ }^{6}$ Centre for Population Health Research, Curtin University of Technology, Bentley, WA, Australia. ${ }^{7}$ School of Pathology and Laboratory Medicine, University of Western Australia, Nedlands, WA, Australia. ${ }^{8}$ Centre for Comparative Genomics, Murdoch University, Murdoch, WA, Australia.

Received: 4 November 2015 Accepted: 16 March 2016

Published online: 24 March 2016

\section{References}

1. EURORDIS. What is a rare disease? European Organisation for Rare Diseases; 2010. http://www.eurordis.org/sites/default/files/publications/Fact_Sheet_ RD.pdf. Accessed 18 March 2016.

2. Orphanet. The portal for rare diseases and orphan drugs. About rare diseases. 2012 [cited 201619 February]. Available from: http://www.orpha. net/consor/cgi-bin/Education_AboutRareDiseases.php?lng=EN.

3. Barrera LA, Galindo GC. Ethical aspects on rare diseases. In: Posada de la Paz M, Groft SC, editors. Rare diseases epidemiology. Advances in experimental medicine and biology, vol. 686. Netherlands: Springer; 2010. p. 493-511.

4. Hordinsky M, Donati A. Alopecia areata: an evidence-based treatment update. Am J Clin Dermatol. 2014;15(3):231-46. PubMed PMID: 25000998.

5. Bogershausen N, Wollnik B. Unmasking Kabuki syndrome. Clin Genet. 2013; 83(3):201-11.

6. European Commission. Rare diseases - what are they? 2013 [cited 19 February 2016]. Available from: http://ec.europa.eu/health/rare_diseases/ policy/index_en.htm.
7. Jaffe A, Zurynski Y, Beville L, Elliott E. Call for a national plan for rare diseases. J Paediatr Child Health. 2009;46:2-4.

8. EURORDIS. Rare diseases: understanding this public health priority. European Organization for Rare Diseases; 2005. http://www.eurordis.org/ IMG/pdf/princeps_document-EN.pdf. Accessed 18 March 2016.

9. Francaise R. French national plan for rare diseases 2005-2008: ensuring equity in the access to diagnosis, treatment and provision of care. 2004.

10. Limb L, Nutt S, Sen A. Experiences of rare diseases: an insight from patients and families. Rare Disease UK; 2010. http://www.raredisease.org.uk/ documents/RDUK-Family-Report.pdf?bcsi_scan_c221d61a0ea4ff4c=0\&bcsi_ scan_filename=RDUK-Family-Report.pdf. Accessed 18 March 2016.

11. Therapies SHG. Rare disease impact report: insights from patients and the medical community Shire. 2013.

12. Dawkins $\mathrm{H}$, Molster $\mathrm{C}$, Youngs $\mathrm{L}$, O'Leary P. Awakening Australia to rare diseases: symposium report and preliminary outcomes. Orphanet J Rare Dis. 2011;6:57. Epub 18 August 2011.

13. Molster C, Youngs L, Hammond E, Dawkins H. Key outcomes from stakeholder workshops at a symposium to inform the development of an Australian national plan for rare diseases. Orphanet J Rare Dis. 2012;7:50. Epub 10 August 2012.

14. Anderson M, Elliott EJ, Zurynski YA. Australian families living with rare disease: experiences of diagnosis, health services use and needs for psychosocial support. Orphanet J Rare Dis. 2013;8:22.

15. Nutt S, Limb L. Survey of patients' and families' experiences of rare diseases reinforces calls for a rare disease strategy. Soc Care Neurodisability. 2011; 2(4):195-9.

16. EURORDIS. EurordisCare 2: Survey of the delay in diagnosis for 8 rare diseases in Europe. European Organisation for Rare Diseases; 2004. http:// www.eurordis.org/IMG/pdf/Fact_Sheet_Eurordiscare2.pdf. Accessed 18 March 2016.

17. Department of Health Western Australia. WA rare diseases strategic framework 2015-2018. Perth: Department of Health WA; 2015.

18. Bombak AE. Self-rated health and public health: a critical perspective. Front Public Health. 2013;1:15. PMCID: 3855002.

19. DeSalvo KB, Bloser N, Reynolds K, He J, Muntner P. Mortality prediction with a single general self-rated health question. A meta-analysis. J Gen Intern Med. 2006:21(3):267-75. PMCID: 1828094.

20. Australian Bureau of Statistics. Australian Demographic Statistics, December 2010 2011. Available from: http://www.abs.gov.au/AUSSTATS/abs@.nsf/ Lookup/3101.0Main+Features1Dec\%202010. Accessed 18 March 2016.

21. Orphanet. Linearisation rules for rare diseases, Orphanet procedural document. Paris: Orphanet; 2014.

22. Australian Bureau of Statistics. Australian health survey: health service usage and health related actions, 2011-12. Canberra: Australian Government; 2013.

23. Blum R, Garrel D, Hodgman C, Jorissen T, Okinow N, Orr D, et al. Transition from child-centered to adult health-care systems for adolescents with chronic conditions. A position paper of the Society for Adolescent Medicine. J Adolesc Health. 1993;14(7):570-6.

24. Richesson R, Vehik K. Patient registries: Utility, validity and inference. Adv Exp Med Biol. 2010;686:87-104.

25. EURORDIS. The voice of 12,000 patients: experiences and expectations of rare disease patients on diagnosis and care in Europe. European Organization for Rare Diseases; 2009. Available at: http://www.eurordis.org/ IMG/pdf/voice_12000_patients/EURORDISCARE_FULLBOOKr.pdf?bcsi_scan_ c221d61a0ea4ff4c=0\&bcsi_scan_filename=EURORDISCARE_FULLBOOKr.pdf. Accessed 18 March 2016.

26. Gliklich R, Leavy M. Patient registries and rare diseases. Appl Clin Trials. 2011; 20(3):35-44.

27. Limb L, Nutt S. Improving lives, optimising resources: a vision for the UK rare disease strategy. Rare Disease UK; 2011. Available at: http://www. raredisease.org.uk/documents/RD-UK-Strategy-Report.pdf?bcsi_scan_ c221d61a0ea4ff4c=0\&bcsi_scan_filename=RD-UK-Strategy-Report.pdf. Accessed 18 March 2016.

28. Department of Health Western Australia. WA chronic health conditions framework 2011-2016. Perth: Department of Health Western Australia; 2011.

29. National Health Priority Action Council. National chronic disease strategy. Canberra: Australian Government Department of Health and Ageing; 2006.

30. Council of Australian Governments (COAG). National disablity strategy 2010-2020. Canberra: Commonwealth of Australia; 2011.

31. National Health and Hospital Reform Commission. A healthier future for all Australians final report. Canberra: Commonwealth of Australia; 2009. 
32. Ouwens M, Wollersheim H, Hermens R, Hulscher M, Grol R. Integrated care programmes for chronically ill patients: a review of systematic reviews. Int J Qual Health Care. 2005;17(2):141-6.

33. Aymé $\mathrm{S}$, Rodwell C. Report on the state of the art of rare disease activities in Europe of the European Union Committee of Experts on Rare Diseases Part I: Overview of rare disease activities in Europe and key developments in 2010. 2011.

34. European Union Committee of Experts on Rare Diseases (EUCERD). EUCERD workshop report: National centres of expertise for rare diseases \& European collaboration between centres of expertise. 2011.

35. Šimerka P. Council Recommendation of 8 June 2009 on an action in the field of rare diseases. Off J Eur Union. 2009;2009/C 151/02:7-10.

36. Department of Health Western Australia. Paediatric chronic diseases transition framework. Perth: Health Networks Branch, Department of Health; 2009.

37. Zurynski Y, Elliott E. Challenges of transition to adult health services for patients with rare diseases. What can be done for young people stuck in "health care limbo" when they leave paediatric services? Med J Aust. 2013; 198(11):575-6.

38. Dye D, Brameld K, Maxwell S, Goldblatt J, O'Leary P. The impact of single gene and chromosomal disorders on hospital admissions in an adult population. J Community Genet. 2011;2:81-90. Epub 13 March 2011.

39. EURORDIS. The voice of rare disease patients: experiences and expectations of over 3,000 patients on rare disease patient registries in Europe. European Organization for Rare Diseases; 2013. Available at: http://download.eurordis. org.s3.amazonaws.com/the-voice-of-rare-disease-patients.pdf?bcsi_scan_ c221d61a0ea4ff4c=0\&bcsi_scan_filename=the-voice-of-rare-disease-patients. pdf. Accessed 18 March 2016.

40. Taruscio D, Vittozzi L, Choquet R, Heimdal K, Iskrov G, Kodra Y, et al. National registries of rare diseases in Europe: an overview of the current situation and experiences. Public Health Genomics. 2015;18:20-5.

41. Department of Health Western Australia. Scoping paper on the need for a national rare diseases plan for Australia. Perth: Government of Western Australia; 2013.

\section{Submit your next manuscript to BioMed Central and we will help you at every step:}

- We accept pre-submission inquiries

- Our selector tool helps you to find the most relevant journal

- We provide round the clock customer support

- Convenient online submission

- Thorough peer review

- Inclusion in PubMed and all major indexing services

- Maximum visibility for your research

Submit your manuscript at www.biomedcentral.com/submit

O) BioMed Central 